\section{Diplomacia preventiva (¿y ciudadana?) y cooperación para la paz en América Latina: Los grupos nacionales de amigos de Colombia ${ }^{1}$}

\author{
Preventive (and citizen?) diplomacy and cooperation for the \\ peace in Latin-American: \\ The national groups of friends for the peace in Colombia
}

DOI: 10.5752/P.2317-773X.2016v4.n2.p113

Nestor Guerrero Soto²

Recebido em: 04 de outubro de 2016

Aprovado em: 16 de janeiro de 2017

\begin{abstract}
RESUMEN
Como país acompañante del proceso de negociaciones entre el gobierno colombiano y las FARC-EP (2012-2016), Chile propuso la formación de "grupos nacionales de amigos por la paz en Colombia". Este artículo realiza una primera aproximación a dicho proceso, analizando el contexto y conformación de los grupos, sus objetivos y los aportes que podrían realizar en la etapa de postconflicto e implementación de los acuerdos de paz. Estos grupos, presentes en ochos países de la región, expresarían una forma renovada de diplomacia preventiva y cooperación para la paz en América Latina, erigiéndose como uno de los pilares de la infraestructura regional para la paz. Mediante el análisis de fuentes públicas de información y sobre la base de literatura especializada, se concluye que los grupos nacionales de amigos por la paz en Colombia constituyen una red regional de cooperación que será clave en la fase del post-conflicto, pero que debe ampliarse hacia otros sectores de las sociedades latinoamericanas, especialmente hacia las bases alejadas de la política central para ser una expresión de diplomacia ciudadana.
\end{abstract}

Palabras clave: Diplomacia; Cooperación Regional; Paz; Solidaridad Internacional; Relaciones Sur-Sur

\section{ABstract}

As an accompanist country of the negotiation process between Colombia's government and FARC-EP (2012-2016), Chile proposed the conformation of "national groups of friends for the peace in Colombia". This paper makes a first approach to the process, analyzing the context and conformation of the groups, their aims, and contributions that they could make in the post-conflict phase and implementation of the agreement peace. Those groups, formed in eight countries of the region, could show a renewed expression of preventive diplomacy and cooperation for peace in Latin America, establishing itself as a pillar of the regional infrastructure for peace. Through the analysis of
1. Este artículo es parte del proyecto de investigación "Interméstico: análisis y sistematización del rol de Chile en las negociaciones para el proceso de paz en Colombia" (Proyecto E102016), financiado por el Concurso Anepe 2016 convocado por el Departamento de Investigación de la Academia Nacional de Estudios Políticos y Estratégicos, del cual el autor es investigador principal. Agradezco a Rodrigo Matamoros y Fernando Contardo, co-investigadores. Agradezco, asimismo, a Luis Maira y Milenko Skoknic por entrevistas concedidas, a Francisco Aranguiz de RIAL por su colaboración, y a los evaluadores de "Estudos Internacionais" por sus sugerencias que han permitido obtener una versión mejorada del artículo. La responsabilidad sobre el mismo es, en cualquier caso, exclusiva del autor. Este artículo no representa ninguna posición institucional, ni del Ministerio de Relaciones Exteriores de Chile, donde trabaja el autor, ni del Ministerio de Defensa Nacional de Chile, que ampara a la ANEPE.

2. Licenciado en Ciencias Políticas, Administrador Público y Magíster en Ciencia Política por la Universidad de Chile. Ha publicado artículos en diferentes revistas latinoamericanas y es autor del libro "Abogados prestigiados, intelectuales públicos, líderes laicos y religiosos" (CLACSO 2015). ORCID:orcid. org/0000-0001-8339-3708. 
3. No es objetivo de este artículo realizar una descripción, seguimiento o análisis del proceso de negociaciones y sus resultados entre el gobierno colombiano y las FARC-EP. Simplemente notar que durante la revisión de este artículo se produjo el plebiscito (02 de octubre de 2016) que sometió el acuerdo definitivo a la voluntad soberana del pueblo colombiano que, por estrecho margen, decidió su rechazo. Tras ello las partes ajustaron el acuerdo final, el que fue aprobado por el Congreso Nacional. Actualmente ya comenzó la etapa de implementación y verificación de los puntos acordados. Toda la información puede verse en la Oficina del Alto Comisionado para la Paz (http://www. altocomisionadoparalapaz.gov.co/). public sources of information and specialized bibliography, it is concluded that "national groups of friends for the peace in Colombia" are a regional network of cooperation that will be key in the post-conflict phase. Nevertheless, its expansion to others Latin-American social sectors is needed, especially to the sectors away from the central politics to become an expression of citizen diplomacy.

Key words: Diplomacy; Regional Cooperation; Peace; International Solidarity; South-South Relations

Introducción

En el marco del vigente proceso de diálogo, establecimiento e implementación de acuerdos de paz entre el Gobierno colombiano y las Fuerzas Armadas Revolucionarias de Colombia-Ejército del Pueblo (FARC-EP), las delegaciones anunciaron el 24 de agosto de 2016 que habían alcanzado "un Acuerdo Final, integral y definitivo, sobre la totalidad de los puntos de la Agenda del Acuerdo General para la Terminación del Conflicto y la Construcción de una Paz Estable y Duradera en Colombia”. El anuncio del histórico logro se informó mediante un comunicado conjunto, en cuyo tercer párrafo preambular las partes recuerdan que "la República Bolivariana de Venezuela y la República de Chile se han aprestado en todo momento a sus buenos oficios como países acompañantes"”.

Considerando los aprendizajes a partir de la experiencia acumulada, se requería crear un entorno internacional favorable, generando las condiciones para que la región se constituya en un soporte para la paz y no en un impedimento. Al mismo tiempo, se necesitaba disponer de acompañamiento y verificación internacional. En esa dimensión de internacionalización del proceso, y para otorgar seguridades a las partes, se acordó convocar países garantes: Noruega y Cuba, y países acompañantes: Venezuela y Chile. El rol de Chile en el proceso posee varias aristas y ámbitos de acción, pudiendo explicarse a partir de una combinación de factores en que se conjugan valores, principios e intereses.

Un ámbito de acción poco conocido, liderado por Chile en su rol de país acompañante del proceso de paz, ha sido la convocatoria a conformar grupos de amigos por la paz en Colombia. Lo novedoso de la iniciativa radica en que los grupos (o comités) se han formado al interior de varios países de la región, integrados por personalidades influyentes del quehacer nacional, en circunstancias que la conformación de grupos de amigos ha sido un fenómeno tradicionalmente caracterizado por el hecho que varios países, en tanto Estados-nacionales, se reúnen en torno a temas de interés común para promoverlos en la esfera internacional. Incluso cuando se trata de su expresión tradicional, los grupos de amigos constituyen un aspecto escasamente estudiado sobre el rol de grupos informales en la resolución de conflictos en la era de la Post Guerra Fría en circunstancias que su aporte podría considerarse como un elemento crítico de un incipiente sistema de gobernanza global de seguridad (WHITFIELD, 2007).

Así, la conformación de grupos nacionales de amigos por la paz en Colombia sería un caso hasta ahora atípico en la región y en procesos internacionales que puede adscribirse, como se verá a lo largo del docu- 
mento, a una de las herramientas disponibles de la diplomacia preventiva, y que se suma a otros medios de acción, como los buenos oficios, las misiones especiales o las operaciones de mantenimiento de la paz, todas generalmente ancladas al marco de las Naciones Unidas. En particular, la formación de los grupos nacionales de amigos expresaría una forma renovada de diplomacia preventiva y cooperación para la paz en América Latina, erigiéndose como uno de los pilares de la infraestructura regional para la paz.

Se trataría de un dispositivo que combina los distintos tracks o vías de la diplomacia en su rol de prevención, mediación y resolución de conflictos. Los tracks de la diplomacia son las vías de intermediación en la mediación y resolución de conflictos de forma preventiva y su clasificación en tres tipos, como se verá, obedece al tipo de actores y canales involucrados: vía oficial, no-oficial y no-oficial dirigida a la sociedad en general. Al señalar que el dispositivo "grupos nacionales de amigos" combinaría las distintas vías de la diplomacia para contribuir con la paz en Colombia, se puede deducir que se está frente a un soporte integral para la paz, en el que participan actores institucionales y no-institucionales en una lógica top-down y bottom-up, evidenciando una manifestación de diplomacia ciudadana.

El representante de Chile en el proceso de paz en Colombia, Luis Maira, señaló que la conformación de los grupos nacionales por la paz en varios países de la región, es "un triunfo moral para la diplomacia chilena". Chile, de forma altruista, "organizó el apoyo latinoamericano a la paz". Este logro diplomático obliga cuestionarse: ¿en qué países se han conformado estos grupos nacionales de amigos por la paz en Colombia?, ¿por qué en esos países?, ¿quiénes los conforman y qué objetivos tienen?, ¿la conformación de los grupos responde efectivamente a una combinación de los tracks de la diplomacia preventiva?, y por último ¿asistimos a una nueva forma de cooperación para la paz en la región? Estas son algunas de las preguntas que inspiran el artículo, cuyo objetivo principal es describir, contextualizar y analizar la iniciativa chilena para la formación de grupos nacionales de amigos por la paz en Colombia en América Latina a la luz de la noción de diplomacia preventiva y ciudadana, así como de la propia trayectoria de cooperación para la paz en la región, en el contexto más amplio de relacionamiento estratégico entre Chile y Colombia en el actual escenario político regional.

Metodológicamente, además de consultar literatura especializada y revisar documentos clave, la información para analizar el caso de estudio se ha recolectado de fuentes públicas de acceso abierto, tales como comunicados oficiales, prensa, notas diplomáticas, conferencias públicas y reseñas biográficas y curriculares. Pero dado que se trata de un caso de estudio contingente, cabe tomar en cuenta dos advertencias investigativas cuando se analizan iniciativas de diplomacia preventiva y/o ciudadana, en tanto el caso estudiado contiene elementos de tales fenómenos. Primero, que estas iniciativas suelen mantener un perfil discreto y de reserva, lo que dificulta su investigación empírica, y segundo, tratándose de acciones en fase de inicio o en pleno desarrollo, resulta complejo evaluar sus logros y resultados, sea en los procesos de paz o en la influencia sobre la
4. Conferencia de Luis Maira, Representante de Chile en los Diálogos de Paz, en Instituto Latinoamericano de Relaciones Internacionales - Universidad Miguel de Cervantes, Santiago, 20 de julio de 2016. 
diplomacia tradicional y las posiciones gubernamentales (SERBIN, 2010; WHITFIELD, 2007).

De esa forma, además de esta introducción, el artículo se inicia con una breve revisión al concepto de diplomacia preventiva mostrando su evolución reciente (sección I), para luego enmarcar el caso de estudio mediante la trayectoria que ha tenido la cooperación para la paz en América Latina vinculada a los mecanismos de concertación política e integración regional, con énfasis en el caso colombiano (sección II). Enseguida se expone una nota sobre los fundamentos geopolíticos y diplomáticos del rol de Chile como acompañante del proceso de paz en Colombia (sección III), para así, con tales antecedentes empíricos y conceptuales, analizar la conformación de los grupos nacionales por la paz en Colombia, caracterizándolos y observando las tendencias predominantes de sus integrantes, además de reseñar sus objetivos y desafíos (sección IV). La última parte intenta producir un diálogo entre las categorías teóricas y el caso estudiado interrogando sobre la existencia de una nueva forma de cooperación para la paz (sección V). Al concluir se expone la bibliografía y fuentes consultadas y un anexo que detalla los nombres, ocupaciones y afinidad política de cada uno de los integrantes de los ocho grupos nacionales de amigos de Colombia.

Diplomacia preventiva e internacionalización de la paz

En 1992, el Secretario General de las Naciones Unidas, Boutros Boutros-Ghali, presentó ante la Asamblea General su informe "Un programa de paz: diplomacia preventiva, establecimiento de la paz y mantenimiento de la paz", que se basó en el diagnóstico de inacción de la Organización durante la Guerra Fría. El Informe constituía un llamado y una nueva oportunidad para alcanzar los objetivos fundamentales de la Carta de Naciones Unidas, especialmente el propósito de mantener la paz y seguridad internacionales, para lo cual se debe prevenir, administrar y preservar la paz en situaciones de conflicto, y luego ayudar a consolidar la paz en sus distintos contextos restableciendo las instituciones y la infraestructura. En una perspectiva aún más integral, señaló el Informe, las sociedades deberían hacerse cargo de las causas más profundas de los conflictos: la desesperación económica, la injusticia social y la opresión política.

La diplomacia preventiva fue definida como "las medidas destinadas a evitar que surjan controversias entre dos o más partes, a evitar que las controversias existentes se transformen en conflictos y a evitar que éstos, si ocurren, se extiendan” (BOUTROS-GHALI, 1992). Según lo anterior, la noción de diplomacia preventiva "es uno de los grandes conceptos de las Naciones Unidas que persistirán durante toda la existencia de la Organización mundial; porque esa idea se sustenta en la sencilla convicción de que es preciso considerar todo aquello que pueda hacerse para prevenir las crisis o los conflictos" (ONU, 2011), incluyendo las causas más profundas de los mismos, y hoy, qué duda cabe, su relación con la democracia y los derechos humanos. La diplomacia preventiva se encuentra ligada al sexto capítulo de la Carta de las Naciones Unidas sobre arreglo pacífico de controversias, vinculándola con los clásicos medios de solu- 
ción pacífica de conflictos: la negociación, la investigación, la mediación, la conciliación, el arbitraje, el arreglo judicial, el recurso a organismos o acuerdos regionales u otros medios pacíficos de su elección. Con más precisión, el Informe presentado por Boutros-Ghali sistematizó y abogó por los siguientes mecanismos de diplomacia preventiva: medidas para consolidar la confianza; la investigación de los hechos; la alerta temprana; el despliegue preventivo; y las zonas desmilitarizadas. En una perspectiva más amplia -consistente con el enfoque adoptado- son instrumentos de la diplomacia preventiva: la Comisión de la Consolidación de la Paz, los Buenos Oficios del Secretario General, los enviados, las oficinas regionales, las misiones políticas sobre el terreno, las operaciones de mantenimiento de la paz, los grupos de amigos y otros tipos de apoyo diplomático (KI-MOON, 2011). Como se aprecia, existe un set amplio y variado de instrumentos que ponen en práctica, en el terreno, los fines de la diplomacia preventiva. Los grupos de amigos son parte de ese instrumental.

Algunos de estos instrumentos no se ajustan estrictamente a las lógicas de la prevención, pero al tener como objetivo evitar el resurgimiento de los conflictos, la noción de diplomacia preventiva opera flexible y adaptativamente. De hecho, el concepto tiene una dimensión de prevención post-conflicto: pretende evitar su extensión una vez ocurridas las controversias o su reiteración una vez resueltas. Por esto, la categoría se encuentra fuertemente vinculada al mantenimiento y consolidación de la paz, cuando el post-conflicto se torna una etapa trascendental para procurar la estabilidad y reforzar la paz y seguridad internacionales (Academia Diplomática San Carlos-Centro de Pensamiento Estratégico, 2012). La consolidación de la paz es la contraparte de la diplomacia preventiva, y ambas se sostienen mutuamente. De tal forma, el encadenamiento conceptual sería el siguiente: la seguridad colectiva se alimenta de las acciones de diplomacia preventiva en un marco de cooperación para la paz, y los grupos informales en la esfera internacional, como los grupos de amigos, constituyen una forma de diplomacia preventiva.

Desde la perspectiva del soporte regional a las acciones de diplomacia preventiva, la Carta de las Naciones Unidas otorga el margen necesario para que distintos grupos de Estados actúen con suficiente flexibilidad para tratar los asuntos que ameriten el involucramiento regional, incluyendo:

(...) organizaciones creadas en virtud de tratados, organizaciones regionales de seguridad y defensa, organizaciones para promover el desarrollo regional en general o la cooperación respecto de alguna cuestión o función económica en particular, y agrupaciones creadas para tratar alguna cuestión concreta de actualidad de carácter político, económico o social. (Boutros-Ghali, 1992, p. 19).

Sobre la importancia de este soporte regional en las tareas de diplomacia preventiva, el Informe de Boutros-Ghali releva la necesidad de tener en cuenta las especificidades de los contextos en que los conflictos surgen y las fórmulas que cada área geográfica puede darse para contribuir a su prevención o resolución. En el caso latinoamericano, que se profundiza más adelante, son muy importantes las experiencias de El Salvador y Nicaragua. En el primer caso, los "colaboradores del Secretario General" contribuyeron con los acuerdos de paz entre el gobierno y el 
5. Sobre este punto, gran parte de la utilidad potencial de los grupos informales que cooperan en la esfera internacional radica en su flexibilidad. De hecho, un solo mecanismo puede apoyar las actividades de pacificación que van desde las consultas que preceden a las negociaciones hasta la mediación y la implementación de un acuerdo de paz, sin importar qué combinación de actores pueda llevar a cabo la intervención (WHITFIELD, 2007)
Frente Farabundo Martí para la Liberación Nacional (FMLN). La experiencia salvadoreña suele ser presentada por la literatura como un notable caso de éxito de resolución de conflictos mediante una operación de paz multidimensional, en que la figura del "grupo de amigos" -formado por países- desempeñó un rol clave (WHITFIELD, 2007; DOYLE, JOHNSTONE, ORR, 2002). En el segundo caso, el fin del conflicto en Nicaragua "requirió una operación sumamente compleja iniciada por dirigentes de la región y llevada a cabo por distintos Estados, agrupaciones de Estados y la Organización de Estados Americanos" (BOUTROS-GHALI, 1992). El Grupo de Contadora -que reunió a Colombia, México, Panamá y Venezuela- es una típica expresión de los esfuerzos de gestión político-diplomática para la paz en Centroamérica en la década de los ochenta.

En esta dimensión de cooperación regional para la paz, la acción regional implica "un mayor grado de participación, consenso y democratización de los asuntos internacionales" (BOUTROS-GHALI, 1992), pero también supone desafíos para la eficacia de la diplomacia preventiva: los sistemas de alerta temprana, la flexibilidad según las necesidades de cada área geográfica o región ${ }^{5}$, las asociaciones de colaboración, la sostenibilidad en el tiempo de las acciones, la importancia de la evaluación y la función crítica de las personas y sus recursos (KI-MOON, 2011). Combinando la necesidad de asociatividad y durabilidad, las acciones de diplomacia preventiva deben trascender a los tomadores de decisiones y los altos cargos (el track uno de la diplomacia), permeando la sociedad civil. En esa perspectiva, además de las alianzas con los mecanismos regionales y la función de las agencias del sistema de Naciones Unidas, es relevante la función que pueden cumplir los mediadores independientes y las instancias de base, como los grupos de ancianos, las organizaciones de la sociedad civil, los grupos de mujeres, los grupos de estudio, la academia, los medios de comunicación y la comunidad empresarial (KI-MOON, 2011). Esta apertura es consistente con la labor diplomática que ejercen actores no tradicionales, con la pérdida de centralidad del Estado como actor unívoco de las relaciones internacionales y con formas innovadoras de cooperación para la paz. Por consiguiente, a pesar del sitial privilegiado que la diplomacia preventiva encuentra en el marco de las Naciones Unidas y en los Estados-nacionales, existen formas emergentes-alternativas para enmarcar los procesos internacionales preventivos.

Diana Chigas (2003) reconoce la existencia de tres vías de intermediación en la mediación y resolución de conflictos de forma preventiva. Son las vías o tracks de la diplomacia. La primera vía es la oficial-gubernamental que se realiza a través de las Naciones Unidas. La segunda vía se hace efectiva en la relación que establecen organizaciones no oficiales experimentadas e imparciales, generalmente ONGs, con las partes en conflicto. La tercera vía se expresa en la intermediación de actores no-oficiales con la sociedad en general, a fin de construir y/o fortalecer las estructuras de las comunidades para consolidar la paz (Academia Diplomática San Carlos-Centro de Pensamiento Estratégico, 2012). Allen y Strimling (2004) dan cuenta de la importancia que ha tenido la cooperación entre actores oficiales y no-oficiales para la prevención y resolución de conflictos complejos incorporando dinámicas top-down y bottom-up y 
destacando el especial papel coordinador de individuos con experiencia en ambos mundos. Es decir, han relevado la necesidad de coordinación entre los tracks uno y dos, cuya cooperación ofrece muchas posibilidades para contribuir, sosteniblemente, a la paz y seguridad, alzándose como un medio efectivo en la resolución de conflictos.

La vía dos de la diplomacia, la no-oficial, también se conoce como "diplomacia ciudadana" y refiere aquellos esfuerzos de construcción de paz activados por personas que no pertenecen a las esferas oficiales del gobierno y que tratan de construir entendimientos y desarrollar ideas para la resolución de conflictos que no han sido suficientemente abordados por los canales oficiales (CHIGAS, 2003; SERBIN, 2010). Generalmente conocidos como "intermediarios", esas personas corresponden a expertos, profesionales y académicos imparciales que facilitan el dialogo entre las partes en conflicto. "Políticamente involucrados y a menudo miembros políticamente influyentes (...). Ellos son parlamentarios, líderes y activistas de movimientos políticos, periodistas, miembros de think tanks, académicos; personas que forman parte del mainstream de sus sociedades y están cerca de la política central” (CHIGAS, 2003, párr. 13).

El track tres de la diplomacia preventiva es el trabajo no-oficial de terceras partes con personas de todos los sectores y ámbitos de la sociedad para encontrar formas de promoción de la paz, bajo la premisa que la paz debe ser construida tanto desde la base en una lógica bottom-up, como desde la cúspide en una lógica top-down (Chigas, 2003). De muy difícil medición, como se advirtió al inicio, la labor de la vía tres de la diplomacia suele estar asociada a factores "subjetivos", como el cambio de actitudes y percepciones. Las contribuciones típicas de las terceras partes no-oficiales son: el cambio de actitudes sobre los "otros" (v. gr. estereotipos y generalizaciones); la apertura de canales de comunicación; el mejoramiento de la calidad de la comunicación; la construcción de relaciones y confianza; el cambio de percepciones del conflicto (mediante la identificación de necesidades, valores e intereses compatibles); la generación de nuevas opciones de negociación; el cambio en la dinámica del conflicto; y el desarrollo de redes sociales como un componente clave de la infraestructura para la paz (CHIGAS, 2003). La idea de construir una infraestructura para la paz parece ser un elemento esencial en la resolución de los conflictos, máxime en las etapas de implementación de los acuerdos.

El término "infraestructuras para la paz" es muy relevante y se relaciona con el desarrollo de mecanismos incluyentes e institucionalizados para la cooperación entre diferentes actores de todos los niveles de la sociedad, en el proceso de construcción de paz y prevención de nuevos conflictos, así como los elementos que ayuden a la consolidación y sostenibilidad de la paz. La infraestructura para la paz requiere un enfoque transversal que, además de campañas y proyectos específicos, contenga una estrategia política con una proyección de implementación a largo plazo (OLIVER, 2012). En las actuales condiciones de fuerte interdependencia y múltiples programas de integración regional, una estrategia política que aspire a desarrollar infraestructuras para la paz en un determinado país exige soporte internacional, especialmente de los países vecinos. 
6. Alguna literatura sobre el involucramiento de terceras partes en conflictos armados internos parece concluir que los actores que intervienen, en tanto tienen intereses y estrategias propias, responderían principalmente a un enfoque realista (Bitar, 2007).

7. Así, el "Grupo de los Ocho" fue conformado por: Colombia, México, Venezuela, Panamá, Argentina, Brasil, Perú y Uruguay. Además del rol para la paz en Centroamérica, este grupo manifestó preocupación por temas de interés regional, tales como la controversia argentino-británica por las Islas Malvinas o la deuda externa de los países latinoamericanos, demostrando la indisociable relación entre paz, cooperación y desarrollo.
Los países vecinos están en una situación especial que los condiciona a colaborar o entorpecer procesos de paz. Como lo demuestra la experiencia de paz en Centroamérica y el "Grupo de Contadora", los países vecinos "son a menudo "halados" hacia la intervención en los conflictos internos gracias a las externalidades que éstos generan y las oportunidades de beneficio que un tipo particular de terminación del conflicto produce" (BITAR, 2007, p. 62). Los países que atraviesan situaciones de conflicto producen efectos desestabilizadores en sus vecindarios: "por un lado, los costos de acomodar grandes cantidades de refugiados, el incremento en el gasto militar para defender las fronteras, el incremento en los costos del transporte y el declive de la reputación de la región frente a inversionistas extranjeros son consecuencias económicas del "derrame" (spillover en el original) de los conflictos internos para los países vecinos" (BITAR, 2007, p. 64-65). Por consiguiente, las acciones de diplomacia preventiva que apunten a desarrollar una infraestructura para la paz deben considerar esa dimensión de soporte internacional, sea por solidaridad con el otro (idealismo), porque vivimos en una sociedad de interdependencia compleja (trasnacionalismo), o simplemente porque resulta conveniente a la propia seguridad de quien coopera (realismo) ${ }^{6}$.

Cooperación para la paz en América Latina

La conformación del "Grupo de Contadora" en 1983 -integrado por Colombia, México, Venezuela y Panamá- para promover conjuntamente la paz en Centroamérica, especialmente en El Salvador, Nicaragua y Guatemala, representa el inicio de una trayectoria de una nueva fase de cooperación para la paz regional. De una motivación inicial centrada en evitar el "derrame" de los conflictos "nacionales" hacia toda la región, parece haberse avanzado hacia una solidaridad que sentaría las bases de nuevas formas de integración regional. Tomando como base la experiencia del "Grupo de Contadora" (que logra la firma del Acta de Paz y Cooperación en Centroamérica en 1984) se formó en 1985 el "Grupo de Apoyo a Contadora" o "Grupo de Lima”, integrado por Argentina, Brasil, Perú y Uruguay. Ambos grupos de países fueron conocidos como el "Grupo de los Ocho"7, que es la base fundamental del "Grupo de Río", un mecanismo permanente de consulta y concertación política de América Latina y el Caribe creado en 1986 mediante la Declaración de Río que, entre otros elementos, expresó que:

(...) el surgimiento de la democracia en América Latina permite un intenso diá-
logo político en el que se reafirma la necesidad de conjugar esfuerzos y capacida-
des para encontrar soluciones propias a nuestras dificultades e impulsar el desar-
rollo independiente y sostenido en la región, nos une el propósito de fortalecer
la democracia a partir de un vigoroso desarrollo económico y social de nuestra
región, basado en un creciente proceso de cooperación e integración en América
Latina. (Declaración de Río, 1986, párr. 2).

Como se puede apreciar, la Declaración establece una relación causal de desarrollo regional basado en la cooperación e integración. De hecho, de los ocho objetivos que la Declaración de Río manifiesta, el término "cooperación" está presente en cinco de ellos. Al "Grupo de Río" se adhirieron progresivamente el resto de países de la región, hasta que el 
año 2010 se realizó la XXI y última reunión, transformándose en la actual "Comunidad de Estados Latinoamericanos y Caribeños" (CELAC).

La diplomacia preventiva, la cooperación y la mediación entre Estados tienen antecedentes muy importantes -y antiquísimos- en la región ${ }^{8}$. Quizás la fase contemporánea de experiencias cooperativas se inició precisamente con el Grupo de Contadora y ha tenido destacables expresiones a partir de la década del 2000. En el ámbito hemisférico bajo el marco de la "Organización de Estados Americanos" (OEA) se encuentran la Carta Democrática Interamericana (2001), que contiene mecanismos de diplomacia preventiva para gestionar políticamente alteraciones al orden democrático-constitucional, y la Declaración sobre Seguridad en las Américas (2003). A nivel regional destacan los procesos de integración de la "Unión de Naciones Suramericanas" (UNASUR) el año 2008 y de la ya referida "Comunidad de Estados Latinoamericanos y Caribeños” (CELAC) en 2011.

Respecto a la Declaración sobre Seguridad en las Américas, los Estados reconocen allí la importancia del diálogo y otros esfuerzos nacionales para lograr la solución de situaciones de conflicto interno y alcanzar la reconciliación y una paz justa y duradera. Sobre el papel de las instituciones y mecanismos internacionales, interamericanos y subregionales, esas instituciones pueden desempeñar un rol cuando el Estado afectado así lo manifieste. En el caso colombiano se observa que la inestabilidad regional generada por el conflicto ha estimulado diversas iniciativas de cooperación para la paz, destacando la Declaración de Lima (2001) de la Comunidad Andina, que "ha dado comienzo a un esfuerzo sistemático de aproximaciones a una política de Seguridad Andina, que incluye esfuerzos para acabar con el tráfico de armas y reducir los gastos en defensa en algunos países, y además comprende intercambio de información, acciones comunes, coordinación y desarrollo fronterizo" (RAMÍREZ OCAMPO, 2004, p. 82), y la iniciativa de 2003 de los Jefes de Estado y de Gobierno del "Grupo de Río", que "instaron al Secretario General de la ONU a utilizar sus buenos oficios para impulsar decididamente un proceso de paz en Colombia” (RAMÍREZ OCAMPO, 2004, p. 83), apelando así al track uno (vía oficial) de la diplomacia preventiva. Este hecho solo evidencia la tensión existente entre la internacionalización del conflicto colombiano vis-à-vis la internacionalización de la paz.

Como estrategia política para contener esa dinámica de exportación, el gobierno de Colombia optó por la "internacionalización de la paz" (RAMÍREZ OCAMPO, 2004). Las negociaciones durante el gobierno de Andrés Pastrana y ciertamente el actual proceso de negociaciones bajo el gobierno de Juan Manual Santos (2012-2016) demuestran esa modalidad'. De tal modo, la solución al conflicto colombiano "no parecería probable sin la presencia de la comunidad internacional, entendida como Estados, organismos internacionales y sociedad civil. Su participación es necesaria en las distintas fases de un proceso de paz (...). Como sucedió en Centroamérica, la comunidad internacional será imprescindible al momento de administrar esa paz para garantizar el cumplimiento y la sostenibilidad de los acuerdos" (RAMÍREZ OCAMPO, 2004, p. 84).

En efecto, las últimas cuatro décadas de la política exterior colombiana no se entienden completamente sino no se comprende su estrecha
8. Una publicación identifica como expresión de ello el Tratado de Unión, Liga y Confederación Perpetua (1826); el Tratado de Confederación entre Perú, Bolivia, Chile, Nueva Granada y Ecuador (Lima, 1847-1848); el Tratado de Unión Perú, Chile y Ecuador (Santiago, 1856); la Comisión de Estados Neutrales que intervino para solucionar el conflicto Colombo-Peruano (1934); el Comité de Neutrales (Estados Unidos, Argentina, Brasil, Chile, Perú y Uruguay) que intervino para poner fin al conflicto del Chaco entre Bolivia y Paraguay; el Tratado Interamericano sobre Buenos Oficios y Mediación (Buenos Aires, 1936); el grupo mediador (Argentina, Chile, Brasil y Estados Unidos) que obtuvo el cese a las hostilidades entre Ecuador y Perú en 1941; el Tratado Americano de Soluciones Pacíficas (Pacto de Bogotá), la Comisión Interamericana de Paz (CIP, 1948); las labores de la Organización de Estados Americanos (OEA); y la poco conocida gestión de buenos oficios, facilitación y mediación de Alfonso López M., Canciller de Colombia, en la crisis entre Honduras y El Salvador en 1969 ("guerra del fútbol"), y en el mismo conflicto el rol del Grupo de Cancilleres Centroamericanos (Costa Rica, Nicaragua, Guatemala) y la mediación del ex Presidente peruano José Luis Bustamante y Rivero; finalmente, la mediación del Primer Ministro de Trinidad y Tobago, Dr. Eric Williams (1970), en la controversia fronteriza Surinam-Guyana. Fuente: Academia Diplomática San Carlos-Centro de Pensamiento Estratégico (2012).

9. En los diálogos de paz entre el gobierno Pastrana y las FARC ocurridos entre 1998 y 2002, se conformó un Grupo de Países Amigos de la Paz de Colombia, y se designó un Asesor Especial del Secretario General de las Naciones Unidas para Colombia. Este Grupo se conformó de común acuerdo entre el gobierno y las FARC, que luego designó una comisión facilitadora de 10 países para ejercer los buenos oficios: Canadá, Cuba, España, Francia, Italia, México, Noruega, Suecia, Suiza y Venezuela (Ramírez Ocampo, 2004). 
vinculación con lo que Juan Gabriel Tokatlian (1999) denomina "diplomacia por la paz", esto es, el manejo deliberado de las relaciones internacionales de un país con el objeto específico de lograr apoyo externo para la resolución de una guerra interna. Al respecto, Tokatlian identifica las tres formas puras de solución de aquellos conflictos que podrían denominarse 'intermésticos': i) la Diplomacia por la paz negociada, que supone arreglo del conflicto mediante el diálogo, la negociación y el acuerdo; ii) la Diplomacia por la pacificación forzada, que implica una solución mediante la legitimación de un mayor uso de la fuerza estatal para derrotar al contrincante armado, por la vía política y/o militar; y iii) la Diplomacia por neutralización, cuando la solución del conflicto se hace a través del aislamiento de factores externos (TOKATLIAN, 1999).

En un esfuerzo sistemático de periodizar la historia reciente de Colombia conforme esas modalidades, Tokatlian observa que todas encuentran expresión en distintos gobiernos de ese país, desde la pacificación forzada de finales de los setenta, pasando por los intentos de paz negociada de mediados de los ochenta, la neutralización de fines de esa misma década hasta mediados de los noventa, hasta los nuevos esfuerzos de paz negociada de mediados de los noventa e inicios de los 2000. No obstante, concluye, la diplomacia por la paz fracasó debido a la falta de un cambio sustantivo como respuesta del Estado para conseguir la paz y porque las diplomacias por la paz adolecieron de una estrategia de Estado coherente y nacional en el escenario internacional, es decir, no pudieron construir la infraestructura para la paz. Para el autor, dos tipos de ideas se requieren para que Colombia se beneficie eficazmente de la diplomacia por la paz: "una orientada a diseñar una nueva diplomacia estatal a favor de la paz y otra destinada a crear una diplomacia ciudadana en aras de este mismo objetivo" (TOKATLIAN, 1999, p. 359), entendida esta última como acciones de ciudadanos de un país respecto de terceros países que se expresa en la arena exterior o transnacional (THORUP, 1995 en TOKATLIAN, 1999).

Es fácil advertir la interpelación a los tracks uno, dos y tres de la diplomacia como vías de gestión política internacional para alcanzar la paz en un marco de cooperación, ampliando los actores que pueden soportar y fortalecer la infraestructura para la paz regional más allá de los agentes oficiales. Ésta es la noción de diplomacia ciudadana que, en relación con la agenda de paz y seguridad, merece especial atención en Latinoamérica y el Caribe para trascender la sola declaración de la región como "zona de paz" y avanzar hacia prácticas sociales, políticas y culturales de construcción cotidiana de la paz. Con esa perspectiva, "la concepción de diplomacia ciudadana actualmente promovida en la región responde a una visión más amplia (...) que abarca tanto una diplomacia ciudadana directa, referida a los conflictos entre países o grupos, como a una diplomacia ciudadana multilateral" (SERBIN, 2010, p. 120-121). La diplomacia ciudadana directa, tal como el track tres de la diplomacia (CHIGAS, 2003), se orienta a "contribuir a superar las imágenes y estereotipos negativos entre dos países o entre dos grupos en conflicto, y prevenir la escalada de éste” (SERBIN, 2010, p.128). Debido a esa fuerte carga subjetiva, los componentes de la diplomacia ciudadana deberían tener como objetivos centrales: 
buscar aliados sociales y políticos para una salida negociada al conflicto armado; explorar contactos con grupos y movimientos que puedan presionar positivamente a la guerrilla para iniciar diálogos de paz genuinos; desplegar una labor en la que la defensa de los derechos humanos de todos los colombianos y colombianas sin excepción se convierta en prioritaria; movilizar personalidades destacadas en las artes, la cultura, la ciencia, la educación y las humanidades en la dirección de mostrar que la búsqueda de la paz en el país es sincera y decidida, entre otros (Tokatlian, 1999, p. 360).

Todos los esfuerzos reseñados se inscriben en un esfuerzo mayor cuyo horizonte normativo es consolidar a América Latina y el Caribe como zona de paz y comunidad de seguridad, teniendo en cuenta el paso decisivo que se realizó con la firma del Tratado para la Proscripción de Armas Nucleares en América Latina y el Caribe (Tratado de Tlatelolco, 1967) que declaró la desnuclearización del territorio de los países signatarios. Pues bien, de esa noción de seguridad propia de la Guerra Fría y basada en la agenda clásica que jerarquiza los tipos de amenaza, la región ha transitado hacia una noción de seguridad multidimensional, lo que queda expresado en la Declaración de Seguridad de las Américas al prescribir que:

\begin{abstract}
Nuestra nueva concepción de la seguridad en el Hemisferio es de alcance multidimensional, incluye las amenazas tradicionales y las nuevas amenazas, preocupaciones y otros desafíos a la seguridad de los Estados del Hemisferio, incorpora las prioridades de cada Estado, contribuye a la consolidación de la paz, al desarrollo integral y a la justicia social, y se basa en valores democráticos, el respeto, la promoción y defensa de los derechos humanos, la solidaridad, la cooperación y el respeto a la soberanía nacional (OEA, 2003).
\end{abstract}

Bajo tales premisas y en esa trayectoria histórica, el conflicto en Colombia representa, tal vez, uno de los principales desafíos para avanzar hacia la consolidación de la paz, lo que no implica, cabe decirlo, el pleno logro de la seguridad bajo un enfoque multidimensional en la región. Sin embargo, las acciones de diplomacia preventiva y ciudadana mediante una combinación de sus tracks adquieren alta importancia en ese camino de construcción de una infraestructura para la paz en la región.

Geopolítica y diplomacia: ¿por qué Chile contribuye con

la paz en Colombia? ${ }^{10}$

Los orígenes del rol de Chile como país acompañante en las negociaciones entre el gobierno de Colombia y las FARC-EP hay que buscarlos el año 2012. Mientras el Gobierno de Chile era encabezado por el ex Presidente Sebastián Piñera (liderando la coalición de derecha), Colombia lo lidera el Presidente Juan Manuel Santos. ¿Por qué Colombia invitó a Chile ser parte del proceso como país acompañante? ¿Por qué Chile aceptó? Una combinación estratégica de factores en que se entrelaza la geopolítica y la diplomacia traducida en una mezcla de intereses, valores y principios, pueden configurar una respuesta hipotética a esa decisión política.

Un factor inicial-principal que se sugiere podría explicar la invitación del gobierno colombiano al gobierno chileno a desempeñar el papel de acompañante, es la afinidad ideológica que existía entre Piñera y Santos durante su mandato coincidente, estableciendo esto como posible fórmula de equilibrio político-regional ante los otros países involucrados pertenecientes al bloque del ALBA (Venezuela y Cuba). Colombia y
10. Esta sección del artículo se basa en un escrito previo del autor en el marco del mismo proyecto de investigación al que se adscribe este trabajo. Al respecto, "Principios, intereses y diplomacia: ¿Por qué Chile contribuye con la paz en Colombia?". El Desconcierto (www. eldesconcierto.cl), 16.09.2016, Santiago, Chile. 
11. Discurso de S.E. la Presidenta de

la República, Michelle Bachelet en presentación del libro "Vocación de Paz, la Política Exterior de Chile". 25 de julio de 2016; en https://prensa.presidencia. $\mathrm{cl} /$ discurso. aspx?id=37146.

12. El Objetivo Estratégico №3 del Ministerio de Relaciones Exteriores de

Chile señala: Incrementar y profun-

dizar la Política Exterior Multilateral mediante una activa diplomacia en pro de la Paz y la Seguridad Internacional, la plena vigencia de la Democracia y los Derechos Humanos y la promoción de desarrollo -sostenible y con equidad- en todas sus vertientes. El Objetivo $\mathrm{N}^{\circ} 4$ en tanto, es: Contribuir a la inserción económica de Chile en el mundo, creando las condiciones para nuevas oportunidades de negocios, implementando y profundizando los acuerdos comerciales y apoyando el proceso exportador nacional con énfasis en la pequeña y mediana empresa. Fuente

Ficha Definiciones Estratégicas Año 2015-2018 (Formulario A1), Dirección de Presupuestos (DIPRES), en http://www. dipres.gob.cl/595/articles-144384_doc pdf.pdf.

13. “Se buscó a Chile porque tenía cierto prestigio en justicia y derecho internacional". La Tercera, 23 de junio de 2016; en http://papeldigital.info/ It/?2016062301\#

14. Ejemplo claro de ello es el proyecto coordinado y ejecutado por la Embajada de Chile en Colombia denominado "Foro Internacional: Lecciones Aprendidas de las Transiciones Políticas del Continente para la Construcción de Democracia y Paz", realizado en septiembre de 2015 en Bogotá, y que contó con las intervenciones y experiencias de varios actores participantes de los procesos de Chile, Centroamérica y Colombia.

Resulta especialmente interesante que los expositores chilenos fueran el ex Senador Andrés Allamand (RN) y el ex Ministro Genaro Arriagada (DC) ambos actores político-institucionales fundamentales del proceso chileno de transición a la democracia e integrantes del Grupo Chileno de Amigos para la

Paz en Colombia. Este elemento es confirmado por ambos representantes de Chile en el transcurso del proceso: Milenko Skoknic y Luis Maira.
Chile, como parte de la Alianza del Pacífico, defienden un regionalismo abierto con énfasis comercial, mientras que el ALBA expresa un cierto regionalismo antisistémico con énfasis productivo, político y social, dos modelos posiblemente ubicados en las antípodas de la integración regional (Briceño, 2013; Riggirozzi \& Tussie, 2012).

Un factor subsidiario al anterior que se sugiere, es la tesis sobre los beneficios económicos y comerciales que la paz en Colombia implicaría, pues la solución del conflicto es condición necesaria para el establecimiento de una "comunidad de seguridad", en tanto la estabilidad social y política en Colombia fortalecerá las condiciones para la inversión extranjera, el comercio interno y el comercio exterior (Matamoros \& Contardo, 2016; El Espectador, 2016). Esas condiciones, además de materiales, tienen convergencia en el plano de las ideas, pues existen interrelaciones discursivas entre comercio, acuerdos económicos, paz y seguridad (Strodthoff, 2014).

Tal interpretación permite delinear elementos sobre la aceptación de Chile. Inicialmente al menos, Chile habría tenido en cuenta factores como los descritos, especialmente su pertenencia a la Alianza del Pacífico. Pero en el juego combinado de intereses y principios, estos últimos también informan la decisión. Cuando se presentó el libro que compila la historia de la política exterior chilena, "Vocación de Paz, la Política Exterior de Chile", la actual Presidenta de la República, Michelle Bachelet, aseguró que "históricamente nuestro país ha trabajado por la paz en la región y en el mundo, lo que nos ha llevado a ser distinguidos como el primer país de América Latina en el Índice de Paz Mundial". Ello sería ejemplo "de la capacidad de mantener sólidos principios en política exterior (...) que en democracia han trascendido a los gobiernos y que son la base de la política exterior de Estado", una de cuyos efectos "es el sello que da garantías a nuestra integración a la economía mundial"11. Ello es consecuente con dos objetivos estratégicos de Cancillería que pueden leerse conjuntamente: "incrementar y profundizar la Política Exterior Multilateral, mediante una activa diplomacia en pro de la Paz y la Seguridad Internacional...", y "contribuir a la inserción económica de Chile en el mundo, creando las condiciones para nuevas oportunidades de negocios" ${ }^{\prime \prime 2}$.

Un factor más a tener en cuenta en la decisión político-diplomática adoptada por el gobierno de Chile sería de tipo reputacional. El Representante de Chile en la Mesa de Diálogo por la Paz, Luis Maira, precisó que "se buscó a Chile porque tenía cierto prestigio en justicia y derecho internacional. El Presidente Piñera aceptó, labor que continuó la Presidenta Bachelet por voluntad de Colombia"13. Como un elemento asociado, Chile dispone de una experiencia reciente de transición a la democracia y establecimiento de la verdad histórica después de situaciones de conflicto interno ${ }^{14}$.

Por último, el factor geopolítico-vecinal también formaría parte de la decisión si se considera que la invitación a Chile se produce cuando Perú ya había interpuesto la demanda por el diferendo marítimo de delimitación territorial ante la Corte Internacional de Justicia y el proceso se encuentra en pleno desarrollo, y Bolivia, por su parte, ya había dado señales públicas y político-institucionales sobre una inminente demanda contra Chile ante el mismo organismo sobre la obligación de negociar un acceso soberano al Océano Pacífico. En tal escenario, reforzar lazos de 
amistad y cooperación con países afines podría haber contrarrestado una coyuntura de relaciones vecinales particularmente adversa ${ }^{15}$.

Es fácil advertir, así, un contexto político-regional y bilateral con múltiples factores que configuran un cuadro que enmarca la iniciativa chilena de convocar a la formación de grupos de amigos por la paz de Colombia en varios países de la región. Tal empresa se suma a una trayectoria de diplomacia preventiva y cooperación para la paz en la región signada por el dilema de internacionalización de los conflictos o internacionalización de la paz, sin olvidar la importancia de los "lentes teóricos" desde los cuales observar la cooperación internacional (en su forma ideal-tipo: realismo vs. idealismo).

Los grupos nacionales de amigos por la paz en Colombia

En este trabajo se sugiere que una expresión combinada de los tracks de la diplomacia preventiva en el marco de la cooperación para la paz en América Latina, particularmente como pilar de la infraestructura para la paz, la constituyen los grupos nacionales de amigos para la paz en Colombia. Éstos corresponden a comités nacionales de personalidades influyentes formados en ocho países de la región como una iniciativa de Chile en su rol de país acompañante del proceso de paz en Colombia entre el gobierno nacional y las FARC-EP. Como indica Luis Maira, Representante Chileno en los Diálogos de Paz, "nos dimos cuenta que América Latina estaba a favor de la paz, pero no estaba organizada para apoyarla. Entonces, organizamos ocho Comités Nacionales" ${ }^{\prime \prime}$.

Tradicionalmente, los grupos de amigos se han formado por países (WHITFIELD, 2007; DOYLE, JOHNSTONE, ORR, 2002) y surgen "como alianzas entre Estados que tienen intereses en común- y son un instrumento que expande la labor diplomática y los vuelve influyentes en el orden internacional y en las determinaciones que se adopten como un grupo de respaldo para las acciones que se lleven a cabo" (Academia Diplomática San Carlos-Centro de Pensamiento Estratégico, 2012, p. 47). Teresa Whitfield (2007) distingue cuatro categorías de grupos de amigos: i) los "Amigos del Secretario General", entendidos como grupos informales de Estados formados para dar soporte a los procesos de construcción de paz del Secretario General; ii) los "Amigos de un País" están generalmente alejados del Secretario General o sus representantes y sus objetivos van desde compartir información en situaciones cúspides de la agenda internacional hasta informar y tratar de movilizar atención y recursos hacia conflictos alejados de la "alta política"; iii) los "Grupos de Contacto", alejados de las Naciones Unidas, constituyen vehículos de diplomacia directa entre Estados miembros; y iv) los "Grupos de Implementación y Monitoreo", que han sido establecidos para acuerdos de paz cuya implementación es monitoreada por las operaciones de paz de Naciones Unidas.

Ninguna de estas cuatro categorías logra captar la lógica de los grupos de amigos por la paz en Colombia, aunque mantiene afinidades con los "Amigos de un País" y con los "Grupos de Implementación y Monitoreo". Sin embargo, la idea de conformar grupos de personalidades "al interior" de otros países amigos lo torna una experiencia novedosa en los
15. No obstante, el primer representante chileno en el proceso (2012-2014), Milenko Skoknic, desestima este elemento, en tanto sería extemporáneo. Entrevista realizada en el marco del proyecto de investigación,

16. Conferencia Luis Maira en Facultad de Derecho Universidad de Chile, Santiago, 12 de septiembre de 2016. 
17. Si bien no es parte de las perspectivas de análisis de este trabajo, en clave de género y por la importancia que esta dimensión representa en los procesos de paz, cabe notar que del total de integrantes sumados todos los grupos nacionales, 60 integrantes son hombres y 20 mujeres, en una relación 75\%-25\%. Sobre este tópico, puede leerse la interesante nota de Belén Sanz Luque, representante de ONU Mujeres en Colombia: “Colombia, un proceso de paz con perspectiva de género", El País, 21 de septiembre de 2016 (http://internacional.elpais. com/internacional/2016/09/21/colombia/1474418366_503575.html).

18. Esta denominación proviene de archivo del representante chileno en las negociaciones entre el gobierno colombiano y las FARC, Luis Maira (2014-2016), por cuanto no se identificó información pública sobre la formación de este grupo. procesos de paz y parece ser una forma innovadora de diplomacia preventiva, con elementos de esa tercera vía que busca afectar otros factores como las actitudes y relaciones de los actores, así como la contribución que éstas hagan para cambiar el panorama general del conflicto (CHIGAS, 2003), mediante acciones de diplomacia ciudadana (SERBIN, 2010).

Como muestra el cuadro 1, abajo, los grupos nacionales se han constituido en el período septiembre 2015 - abril 2016 y suman, conjuntamente, 80 integrantes $^{17}$. Corresponden, en general, a destacadas personalidades del quehacer nacional de cada país, ocupando estratégicas posiciones políticas, sociales y culturales, con alta capacidad de influir en la opinión pública. En un nivel de macro-análisis, los países que han conformado grupos nacionales parecen corresponderse con la emergente noción de países like-minded que Chile ha buscado posicionar, es decir, aquellos países con los cuales se comparten principios, intereses y visiones, facilitando un diálogo político privilegiado en áreas estratégicas de desarrollo inclusivo y sostenible, con agendas flexibles que prestan especial importancia a las alianzas público-privadas (Domínguez, Bywaters y García, 2016).

Cuadro 1: Caracterización General Grupos Nacionales de Amigos por la Paz en Colombia

\begin{tabular}{|c|c|c|c|}
\hline País & Fecha Conformación & Integrantes & Auto-identificación \\
\hline Chile & 15 septiembre 2015 & 8 & $\begin{array}{c}\text { Grupo de Amigos de La Paz en } \\
\text { Colombia }\end{array}$ \\
\hline El Salvador & 16 octubre 2015 & 14 & $\begin{array}{c}\text { Grupo Salvadoreño de Amistad } \\
\text { con la Paz para Colombia }\end{array}$ \\
\hline México & 26 noviembre 2015 & 10 & $\begin{array}{c}\text { Grupo de Amigos de México } \\
\text { por la Paz en Colombia }\end{array}$ \\
\hline Aruguay & 14 diciembre 2015 & 7 & $\begin{array}{c}\text { Grupo de Amigos de la Paz en } \\
\text { Colombia en Uruguay }\end{array}$ \\
\hline Brasil & 15 diciembre 2015 & 12 & $\begin{array}{c}\text { Grupo Argentino de Amigos de } \\
\text { Colombia }\end{array}$ \\
\hline Paraguay & 18 marzo 2016 & 8 & $\begin{array}{c}\text { Grupo de Amigos de Brasil para } \\
\text { la Paz en Colombia }\end{array}$ \\
\hline Costa Rica & 6 abril 2016 & 9 & $\begin{array}{c}\text { Grupo Paraguayo de Amigos del } \\
\text { Proceso de Paz de Colombia }\end{array}$ \\
\hline & Total & 80 & $\begin{array}{l}\text { Grupo Costarricense de Amigos } \\
\text { del Proceso de Paz en Colombia }\end{array}$ \\
\hline
\end{tabular}

Fuente: Elaboración propia

Siguiendo el análisis de estos autores y aplicándolo al caso latinoamericano, se advierten ciertas lógicas que tornan consistente que estos países hayan respondido positivamente a la iniciativa chilena. $\mathrm{O}$, desde otro punto de vista, a los que Chile haya convocado en particular. Se trata de países en que Chile despliega una activa política de Cooperación Sur-Sur: El Salvador, Paraguay; de países afines a la Organización para la Cooperación y el Desarrollo Económico (OCDE): Colombia y Costa Rica como candidatos y México como miembro; y de países con los cuales se ha establecido una coalición promotora para revisar los criterios de graduación del Comité de Ayuda Oficial al Desarrollo (CAD): Uruguay y Costa Rica. Los casos "desviados” de Brasil y Argentina se explican, cier- 
tamente, por el peso específico que cada uno tiene en el escenario político regional, sin olvidar en estos dos casos la privilegiada relación bilateral chileno-argentina y la afinidad electiva entre las presidentas Michelle Bachelet y Dilma Rousseff.

Una dimensión más que interesa observar es la que se refiere a los perfiles de los integrantes de los grupos nacionales. Son personalidades del quehacer público nacional, que ocupan posiciones de influencia en el campo político, diplomático, social, académico y/o cultural, con alta capacidad de influir en la opinión pública. Sin pretender un análisis cuantitativo, y como lo muestra el anexo $1^{19}$, predominan los actores políticos-institucionales que son o han sido ministros de Estado, parlamentarios, diplomáticos y funcionarios públicos nacionales e internacionales, incluyendo ex presidentes. Ello es consistente con el cuadro 2 (abajo) que indica que sobre un 50\% de los integrantes (al menos 43 de 80 ) militan en partidos políticos. Luego, una segunda tendencia principal son los académicos e intelectuales, aunque ciertamente existen múltiples casos de pertenencia doble. Una tercera tendencia, finalmente, es aquella que reúne personalidades de la cultura y las artes. Casos mínimos que no representan una tendencia, corresponden a agentes del mundo religioso, del mundo empresarial y de los medios de comunicación. En palabras de Luis Maira, "todos estos Comités - llamados Grupos de Amigos de la Paz en Colombia - son tan amplios que representan la totalidad del espectro político-cultural de cada país"20.

Destacable transversalmente es la participación de varios integrantes de los grupos nacionales en sus respectivos procesos de negociación y acuerdos de paz y transición democrática o acompañando internacionalmente este tipo procesos, de forma principal a través de organismos internacionales regionales y/o universales. En relación con ello, varios integrantes fueron parte de los movimientos de lucha armada y resistencia a gobiernos militares y autoritarios en las décadas de los sesenta, setenta y ochenta en América Latina. Por último, el activismo y defensa de los derechos humanos es otro elemento que caracteriza de modo más o menos general al conjunto.

Cuadro 2: Militancia Integrantes Grupos Nacionales de Amigos por la Paz en Colombia

\begin{tabular}{|c|c|}
\hline Condición & $\mathrm{N}^{\circ}$ \\
\hline Militante & 43 \\
\hline Independiente & 2 \\
\hline Sin Información & \\
\hline & 35 \\
\hline & 80 \\
\hline
\end{tabular}

Fuente: Elaboración propia

Una dimensión más que se intenta reconocer, es la que se refiere a los objetivos planteados al momento de formar los grupos nacionales. El cuadro 3 (abajo) resume los objetivos postulados por cada grupo al momento de su conformación. Observándolos, es fácil advertir que el seguimiento, acompañamiento y apoyo al proceso de paz son los objetivos principales de los grupos nacionales. Se trata de funciones de soporte que recuerdan el proceso de construcción de la infraestructura para la paz.
19. Anexo 1: Integrantes Grupos Nacionales de Amigos por la Paz en Colombia (Cargo/Ocupación y Partido Político").

20. Conferencia Luis Maira en Facultad de Derecho Universidad de Chile, Santiago, 12 de septiembre de 2016.

21. No se pudo identificar información a través de fuentes públicas. 
22. Esta percepción fue recogida de una conversación reservada que el autor sostuvo con un integrante del grupo mexicano (25 de septiembre de 2016).

23. Susana Malcorra en Ceremonia de Presentación "Grupo Argentino de Amigos de Colombia", Palacio San Martín, Buenos Aires, 15 de diciembre de 2015 (https://www.mrecic.gov.ar/la-canciller-malcorra-presento-al-grupo-argentino-de-amigos-de-colombial.

24. Conferencia Luis Maira en Facultad de Derecho Universidad de Chile, Santiago, 12 de septiembre de 2016 .
Existen marcadas diferencias entre objetivos genéricos como los planteados por Brasil, Paraguay y Costa Rica, versus objetivos específicos como los postulados por El Salvador y Argentina. Mientras en el caso salvadoreño destaca el acto de habla "solidarizar" con el proceso, añadiendo la dimensión de respaldo regional, el objetivo argentino avanza un paso e incorpora explícitamente la fase del post-acuerdo.

Cuadro 3: Objetivos Grupos Nacionales de Amigos por la Paz en Colombia

\begin{tabular}{|c|c|}
\hline País & Objetivo \\
\hline Chile & $\begin{array}{l}\text { Hacer un seguimiento cercano a los diálogos por la paz y emitir } \\
\text { declaraciones o dar opiniones de respaldo }\end{array}$ \\
\hline El Salvador & $\begin{array}{c}\text { Solidarizar con el proceso de negociación entre el gobierno de } \\
\text { Colombia y las FARC y hacer más visible el apoyo latinoamericano a } \\
\text { dicho proceso }\end{array}$ \\
\hline México & $\begin{array}{l}\text { Acompañar el diálogo y los acuerdos que se alcancen en el proceso de } \\
\text { paz colombiano }\end{array}$ \\
\hline Argentina & $\begin{array}{l}\text { Respaldar fase de conclusiones y post-acuerdo, buscando acompañar } \\
\text { el diálogo y los acuerdos que alcancen el Gobierno colombiano y las } \\
\text { FARC }\end{array}$ \\
\hline Brasil & $\begin{array}{c}\text { Seguir y apoyar las negociaciones de paz entre el Gobierno } \\
\text { colombiano y las FARC-EP }\end{array}$ \\
\hline Paraguay & Apoyar el proceso de Paz en Colombia \\
\hline Costa Rica & Apoyar el proceso colombiano para el logro de la paz \\
\hline Uruguay & Sin información pública identificada \\
\hline
\end{tabular}

Fuente: Elaboración propia sobre la base de fuentes públicas de información

Respecto al funcionamiento, cada grupo tiene características propias y ha ido operando conforme sus posibilidades. En general, durante la fase de negociaciones los grupos nacionales han emitido declaraciones de apoyo y eventualmente realizado actividades del tipo seminarios o reuniones informativas con altas autoridades. A juicio de un integrante del grupo mexicano, las acciones de soporte que los grupos puedan realizar en esta fase son realmente limitadas debido a la inmediatez con que las informaciones circulan a través de los medios de comunicación vis-à-vis los costos de coordinación de los respectivos grupos ${ }^{22}$. Sin embargo, el valor de los grupos nacionales pareciera radicar en otro lugar. La Canciller argentina Susana Malcorra, al presentar al grupo argentino, expresó que "la paz sólo se logrará con una enorme inversión para generar confianza mutua. Por eso el valor de estos grupos de amigos, que tienen capacidad para dialogar con las partes y pueden convertirse en puente ante las dificultades. Y la importancia de que estos grupos surjan de América Latina, una zona de paz"23. En el largo plazo, afirma Luis Maira "esta gente está dispuesta a seguir como una Red Latinoamericana de Cooperación, apoyando proyectos productivos y sociales replicables" ${ }^{34}$.

¿Una nueva forma de cooperación?

Cuando la Ministra de Relaciones Exteriores de Argentina, Susana Malcorra, presentó al grupo argentino, expresó que "la Cancillería y el Gobierno argentino tendrán un rol, pero la conformación de este grupo de amigos demuestra que los roles importantes en el siglo XXI requieren 
la participación de múltiples actores de la sociedad, una participación plural"25. Con tal sentencia, se evidencia que la construcción y consolidación de la paz no puede basarse únicamente en el papel que desempeñan los Estados y los organismos internacionales formados por éstos: el rol de los actores no estatales, de la sociedad civil y de la sociedad en general es insoslayable para dotar de legitimidad y sostenibilidad a los procesos de paz.

La propuesta chilena de conformar grupos nacionales de amigos por la paz de Colombia, acogida por ocho países de la región, es parte de ese horizonte y aspira a constituir una malla de soporte regional en tanto pilar de la creciente infraestructura para la paz que América Latina ha ido construyendo los últimos años. El análisis de los objetivos de los grupos nacionales, así como sus desafíos confirman lo anterior. En efecto, una red regional de cooperación para la paz de Colombia parece ser un horizonte compartido de las sociedades latinoamericanas. La pregunta es si se está frente a una emergente diplomacia ciudadana en la región o la cooperación inter-estatal aun predomina como marco de acción. Aun no existen elementos suficientes para evaluar el aporte, material y/o simbólico, de los grupos nacionales de amigos como dispositivo innovador de cooperación para la paz en el caso colombiano. Sin duda se trata de un mecanismo de diplomacia preventiva, pero no es tan clara su clasificación como expresión de diplomacia ciudadana, aunque ello siempre dependerá de la propia noción de ciudadanía que se adopte (SERBIN, 2010).

Por otro lado, al observar conjuntamente la conformación de los grupos nacionales a la luz de los perfiles de sus integrantes, se ha establecido que la tendencia que predomina son los agentes político-institucionales, los líderes intelectuales y los activistas culturales que, siguiendo a Chigas (2003), son personas que forman parte del mainstream de sus sociedades y están cerca de la política central. En las lógicas de construcción y consolidación de la paz, los grupos nacionales seguirían representando la modalidad top-down. Parece necesario, por consiguiente, ampliar la red latinoamericana de cooperación para la paz en Colombia hacia las bases de la sociedad, buscando una participación aún más plural mediante la convocatoria a los actores alejados de los núcleos de la política central; dirigentes de base, líderes de movimientos sociales y organizaciones comunitarias.

Considerando un panorama generalizado de desafección política y muy escasa participación política en espacios tradicionales (v. gr. partidos políticos), los aportes que agentes no-oficiales de base puedan realizar para fortalecer formas de cooperación innovadoras resultarán cruciales. Entre estas contribuciones, particularmente en el caso colombiano, destaca el cambio de percepciones del conflicto y, por consiguiente, el cambio de actitudes, estereotipos y generalizaciones sobre los "otros" (CHIGAS, 2003): "narcoguerrilleros" versus "elites corruptas". Los mecanismos de diplomacia ciudadana directa y del tercer track de la diplomacia pueden desempeñar un rol clave en esa dirección.

La ampliación e intensificación de una red latinoamericana de cooperación requerirá, por tanto, una construcción multinivel, multiactor y con fuerte arraigo popular. Lo anterior contribuirá estructuralmente a fomentar y consolidar no solo los procesos de paz coyunturales, como en Colombia, sino que a establecer una cultura de paz en Latinoamérica,
25. Susana Malcorra en Ceremonia de Presentación "Grupo Argentino de Amigos de Colombia", Palacio San Martín, Buenos Aires, 15 de diciembre de 2015 (https://www.mrecic.gov.ar/la-canciller-malcorra-presento-al-grupo-argentino-de-amigos-de-colombia). 
sin olvidar el llamado del Secretario General de Naciones Unidas Boutros Boutros-Ghali (1992), que es hacerse cargo de las causas más profundas de los conflictos: la desesperación económica, la injusticia social y la opresión política.

Finalmente, esta primera aproximación a los grupos nacionales de amigos por la paz en Colombia requerirá nuevos estudios que indaguen empíricamente el tipo de contribuciones al proceso. Mientras, es posible aventurar que se trata de un mecanismo que combina formas tradicionales de cooperación inter-estatal en una lógica top-down con expresiones emergentes de diplomacia ciudadana, pero de ciudadanos que forman parte de aquellas "minorías intensas" fuertemente vinculadas al proceso político y altamente participativas.

Referencias

ACADEMIA DIPLOMÁTICA SAN CARLOS - CENTRO DE PENSAMIENTO ESTRATÉGICO, "Diplomacia Preventiva: Nuevas Perspectivas", en Centro de Información de las Naciones Unidas para Colombia, Ecuador y Venezuela, "Diplomacia Preventiva. Recuperando el Capítulo VI de la Carta de las Naciones Unidas", Bogotá: 2002, pp.39-52.

ALLEN, Susan y Andrea STRIMLING, “Track I - Track II Cooperation”, Beyond Intractability. Ed. Guy Burgess and Heidi Burgess. Conflict Research Consortium, University of Colorado, Colorado, USA: January 2004, Disponibleenhttp://www.beyondintractability.org/essay/track1-2-cooperation.

BITAR, Sebastián, "Dimensiones internacionales de los conflictos armados internos. Perspectivas Internacionales", Cali, Colombia, Vol. 3 N ${ }^{\circ}$, Enero-Junio 2007, pp. 59-68.

BOUTROS-GHALI, Boutros, "Un programa de paz: diplomacia preventiva, establecimiento de la paz y mantenimiento de la paz", Documento Asamblea General/ONU (A/47/277-S/24111), 17 de junio de 1992. Disponible en http://www.un.org/es/comun/docs/?symbol=A/47/277

BRICEÑO, José, "Ejes y modelos en la etapa actual de la integración económica regional en América Latina”. EstudiosInternacionales 175 (2013), pp. 9-39, Santiago.

CHIGAS, Diana, “Track II (Citizen) Diplomacy”, en Beyond Intractability. Ed. Guy Burgess and Heidi Burgess. ConflictResearchConsortium, University of Colorado, Colorado, USA: August 2003. Disponible en http://www.beyondintractability.org/essay/track2-diplomacy.

DOMÍNGUEZ, Ma. del Carmen, Cristóbal BYWATERS y Camila GARCÍA, ”Chile y los países likeminded: hacia una nueva etapa", Revista Diplomacia N¹32. Santiago: 2016, pp.67-72.

DOYLE, Michael, Ian Johnstone \& Robert Orr, "Keeping the peace. Muldimensional UN operations in Cambodia and El Salvador". 2002, Cambridge University Press: UK.

EL ESPECTADOR, "Los beneficios económicos que traerá la paz en Colombia: mayor inversión extranjera y comercio interno", en http://www.americaeconomia.com/economia-mercados/ finanzas/los-beneficios-economicos-que-traera-la-paz-colombia-mayor inversion-extr (26 de agosto de 2016).

GUERRERO, Néstor, "Principios, intereses y diplomacia: ¿Por qué Chile contribuye con la paz en Colombia?", El Desconcierto, 16 de septiembre de 2016 Disponible en: http://www.eldesconcierto.cl/debates-y-combates/2016/09/16/principios-intereses-y-diplomacia-por-que-chile-contribuye-con-la-paz-en-colombia/.

KI-MOON, Ban, "Diplomacia preventiva: obtención de resultados", Informe del Secretario General, Organización de Naciones Unidas, S/2011/552, 26 de agosto de 2011 Disponible enhttp:// www.un.org/ga/search/view_doc.asp?symbol=S/2011/552\&referer=/english/\&Lang=S.

MATAMOROS, Rodrigo \& Fernando Contardo, "Chile y el origen de las negociaciones por la paz en Colombia: Transitando hacia la integración profunda de la región”, artículo no publicado, Proyecto Anepe E10206, Santiago: 2016.

MINISTERIO DE RELACIONES EXTERIORES DE CHILE, Declaración de Río de Janeiro, Río de Janeiro, Brasil, 18 de diciembre de 1986. Dsiponible en: http://www.minrel.gob.cl/minrel/ site/artic/20100415/pags/20100415110701.html. 
OLIVER, Noemí, "La construcción de paz, la Infraestructura para la paz y la cultura de paz. Conceptos y contextos”, Programa de las Naciones Unidas para el Desarrollo, La Paz, Bolivia: 2012.

ORGANIZACIÓN DE ESTADOS AMERICANOS (OEA), "Declaración sobre Seguridad en las Américas", OEA/Ser.K/XXXVIII, Ciudad de México: 28 de octubre de 2003.

ORGANIZACIÓN DE NACIONES UNIDAS (ONU), "La diplomacia preventiva en las Naciones Unidas”, Vol. XLVIII No. 2 2011, Crónica ONU: 2011. Disponible en: https://unchronicle.un.org/ es/article/la-diplomacia-preventiva-en-las-naciones-unidas.

RAMÍREZ OCAMPO, Augusto, "El papel de la comunidad internacional en Colombia”, en ConciliationResources, Alternativas a la guerra: iniciativas y procesos de paz en Colombia, Bogotá: 2004, pp-80-85. Disponible en http://www.c-r.org/downloads/19_El\%20papel\%20de\%20la\%20 comunidad\%20internacional.pdf.

RIGGIROZZI, Pía y Diana Tussie (eds), “The rise of post hegemonic regionalism”. New York: UnitedNationsUniversity Series; 2012, Springer, pp.1-16.

SERBIN, Andrés, "La diplomacia ciudadana en América Latina y el Caribe: una actualización", Política Externa (Sao Paulo), Vol. 8, N 4, Mr/Ab/Mai 2010, pp. 115-130.

STRODTHOFF, Irene, "La interrelación discursiva entre seguridad y acuerdos económicos transpacíficos: las proyecciones regionales de Chile y Australia”, ESD Estudios de Seguridad y Defensa $\mathrm{N}^{\circ} 3$, Junio 2014, Anepe, Santiago.

TOKATLIAN, Juan Gabriel, “Colombia en guerra: las diplomacias por la paz”, Desarrollo Económico, Vol 39, N 155 (Oct-Dec 1999), pp. 339-360.

WHITFIELD, Teresa, "Friends Indeed? The United Nations, Groups of Friends, and the Resolution of Conflict”. 2007, United States Institute of Peace: Washington, DC.

Anexo 1:

Integrantes Grupos Nacionales de Amigos por la Paz en Colombia (Cargo/Ocupación y Partido Político)

\begin{tabular}{|c|c|c|c|}
\hline & Integrante & Rol Histórico / Cargo / Ocupación & Partido Político \\
\hline \multirow{8}{*}{ 睍 } & Isabel Allende & Senadora, Hija Presidente Salvador Allende & Partido Socialista de Chile (PS) \\
\hline & $\begin{array}{l}\text { Andrés } \\
\text { Allamand }\end{array}$ & $\begin{array}{c}\text { Senador, Miembro Acuerdo Nacional para la Transición a } \\
\text { la Plena Democracia (1985) }\end{array}$ & Renovación Nacional (RN) \\
\hline & Hernán Larraín & $\begin{array}{l}\text { Senador, Miembro Inter-American Dialogue } \\
\text { (Washington DC) }\end{array}$ & $\begin{array}{l}\text { Unión Demócrata Independiente } \\
\text { (UDI) }\end{array}$ \\
\hline & Carmen Hertz & $\begin{array}{c}\text { Asesora Cancillería, Ex Embajadora, Activista Derechos } \\
\text { Humanos }\end{array}$ & Partido Comunista de Chile (PC) \\
\hline & José Zalaquett & $\begin{array}{c}\text { Académico, Miembro Comisión Nac. Verdad y } \\
\text { Reconciliación (1990) y Mesa de Diálogo (2000), Ex Pdte. } \\
\text { Amnesty Int }\end{array}$ & $\begin{array}{l}\text { Partido por la Democracia (PPD) } \\
\qquad(-2007)\end{array}$ \\
\hline & $\begin{array}{l}\text { Génaro } \\
\text { Arriagada }\end{array}$ & $\begin{array}{l}\text { Analista Político, Ensayista, Ex Ministro de Estado, Ex } \\
\text { Embajador }\end{array}$ & Democracia Cristiana (DC) \\
\hline & Ángela Jeria & Activista Derechos Humanos, Madre Michelle Bachelet & $\begin{array}{l}\text { Concertación Partidos por la } \\
\text { Democrac }\end{array}$ \\
\hline & $\begin{array}{l}\text { Juan Andrés } \\
\text { Lagos }\end{array}$ & $\begin{array}{l}\text { Encargado Relaciones Internacionales Partido Comunista } \\
\text { de Chile }\end{array}$ & Partido Comunista de Chile (PC) \\
\hline \multirow{3}{*}{ 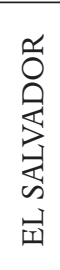 } & $\begin{array}{l}\text { Alfredo } \\
\text { Cristiani }\end{array}$ & Ex Presidente de la República (1989-1994) & Alianza Republicana Nacionalista \\
\hline & Nidia Diaz & $\begin{array}{l}\text { Diputada, Miembro Comisión Negociadora Proceso Paz } \\
\text { FMLN (1989), Miembro COPPPAL }\end{array}$ & FMLN $^{\star}$ \\
\hline & $\begin{array}{l}\text { David Escobar } \\
\text { Galindo }\end{array}$ & $\begin{array}{c}\text { Poeta y Novelista, Miembro Comisión Negociadora } \\
\text { Proceso Paz Gobierno (1990-1992) }\end{array}$ & Sin información pública identificada \\
\hline
\end{tabular}




\begin{tabular}{|c|c|c|c|}
\hline \multirow{11}{*}{ 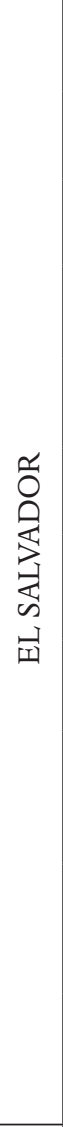 } & $\begin{array}{c}\text { Óscar } \\
\text { Santamaría }\end{array}$ & $\begin{array}{l}\text { Jefe Comisión Negociadora Proceso Paz Gobierno (1989- } \\
\text { 1992), Ex Ministro RREE, Ex Sec. Gral. SICA }\end{array}$ & Sin información pública identificada \\
\hline & Héctor Dada & $\begin{array}{l}\text { Ex Ministro RREE, Miembro Junta Revolucionaria de } \\
\text { Gobierno (1980) }\end{array}$ & Cambio Democrático (CD) \\
\hline & $\begin{array}{l}\text { José María } \\
\text { Tojeira }\end{array}$ & $\begin{array}{l}\text { Sacerdote Jesuita, Ex Rector Universidad Centroamericana } \\
\text { (UCA) (1997-2010) }\end{array}$ & Sin información pública identificada \\
\hline & $\begin{array}{l}\text { Miguez Sáenz } \\
\text { Varela }\end{array}$ & $\begin{array}{c}\text { Director Consejo Directivo Instituto Salvadoreño de } \\
\text { Desarrollo Municipal, Ex Diputado }\end{array}$ & FMLN $^{\star}$ \\
\hline & $\begin{array}{l}\text { Ana Guadalupe } \\
\text { Martínez }\end{array}$ & $\begin{array}{c}\text { Ex Diputada, Miembro Comisión Negociadora } \\
\text { Proceso Paz }\end{array}$ & Partido Demócrata Cristiano (PDC) \\
\hline & $\begin{array}{l}\text { Fidel Chávez } \\
\text { Mena }\end{array}$ & Ex Ministro RREE, Ex Pdte. Asamblea OEA, Ex Diputado & Partido Demócrata Cristiano (PDC) \\
\hline & Francisco Jovel & $\begin{array}{c}\text { Dirigente PRCT (1979-1992), Miembro Comisión } \\
\text { Negociadora Proceso Paz (1992) }\end{array}$ & Sin información pública identificada \\
\hline & $\begin{array}{l}\text { William Alfredo } \\
\text { Hdez. }\end{array}$ & $\begin{array}{c}\text { Diputado, Miembro Grupo Izquierda Parlamentaria } \\
\text { Parlacen }\end{array}$ & FMLN $^{\star}$ \\
\hline & $\begin{array}{l}\text { Amparo } \\
\text { Marroquín }\end{array}$ & $\begin{array}{l}\text { Académica Universidad Centroamericana (UCA), } \\
\text { Miembro Fundación Nacional para el Desarrollo } \\
\text { (FUNDE) }\end{array}$ & Sin información pública identificada \\
\hline & $\begin{array}{l}\text { Eduardo } \\
\text { Sancho }\end{array}$ & $\begin{array}{c}\text { Ex Ejército Revolucionario Pueblo (ERP) y Resistencia } \\
\text { Nacional (RN), Miembro Com. Negociadora } \\
\text { Proceso Paz (1992) }\end{array}$ & FMLN $^{\star}(-1997)$ \\
\hline & $\begin{array}{l}\text { Salvador } \\
\text { Samayoa }\end{array}$ & $\begin{array}{c}\text { Analista Político, Ex Fuerzas Populares de Liberación } \\
\text { (FPL) (1980), Miembro Com. Negociadora } \\
\text { Proceso Paz (1992) }\end{array}$ & FMLN $^{\star}(-1994)$ \\
\hline \multirow{10}{*}{ 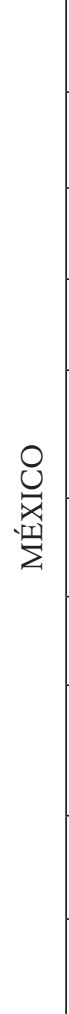 } & $\begin{array}{l}\text { Leonardo } \\
\text { Curzio }\end{array}$ & $\begin{array}{l}\text { Comunicador, Investigador y Analista Político, } 300 \text { Líderes } \\
\text { Influyentes de México (Revista Líderes Mexicanos) }\end{array}$ & Sin información pública identificada \\
\hline & $\begin{array}{l}\text { Juan Ramón de } \\
\text { la Fuente }\end{array}$ & $\begin{array}{l}\text { Académico, Líder Opinión Pública, Ex Secretario de Salud } \\
\text { (1994-1999), Ex Rector UNAM (1999-2007) }\end{array}$ & Independiente \\
\hline & $\begin{array}{c}\text { Enrique } \\
\text { Florescano } \\
\end{array}$ & $\begin{array}{l}\text { Intelectual, Historiador y Asesor/Coordinador de Entidad } \\
\text { y Proyectos Públicos }\end{array}$ & Sin información pública identificada \\
\hline & $\begin{array}{c}\text { Javier } \\
\text { Garciadiego }\end{array}$ & $\begin{array}{l}\text { Historiador, Investigador y Académico, Ex Presidente El } \\
\text { Colegio de México (2005-2010) }\end{array}$ & Sin información pública identificada \\
\hline & $\begin{array}{l}\text { Guadalupe } \\
\text { González }\end{array}$ & $\begin{array}{c}\text { Investigadora y Académica El Colegio de México, } \\
\text { Directora Académica División de Estudios Internacionales } \\
\text { CIDE }\end{array}$ & Sin información pública identificada \\
\hline & Rosario Green & $\begin{array}{l}\text { Diplomática y Embajadora Emérita, Ex Ministra de RREE } \\
\qquad(1998-2000) \text {, Ex Senadora (2006-2012) }\end{array}$ & $\begin{array}{l}\text { Partido Revolucionario Institucional } \\
\text { PRI }\end{array}$ \\
\hline & $\begin{array}{c}\text { Ángeles } \\
\text { Mastretta }\end{array}$ & Escritora y Periodista, Activista Feminista & Sin información pública identificada \\
\hline & $\begin{array}{l}\text { Federico Reyes- } \\
\quad \text { Heroles }\end{array}$ & $\begin{array}{c}\text { Escritor, Investigador y Analista Político, Miembro } \\
\text { Comisión Nac. de los DDHH y Consejero Transparencia } \\
\text { Mexicana }\end{array}$ & Sin información pública identificada \\
\hline & $\begin{array}{l}\text { Bernardo } \\
\text { Sepúlveda }\end{array}$ & $\begin{array}{l}\text { Político y Diplomático, Ex Juez Corte Internacional de } \\
\text { Justicia (2006-2015), Ex Ministro de RREE (1982-1988) }\end{array}$ & $\begin{array}{l}\text { Partido Revolucionario Institucional } \\
\text { PRI }\end{array}$ \\
\hline & Diego Valadés & $\begin{array}{c}\text { Político e Investigador, Ex Procurador General de la } \\
\text { República (1994) }\end{array}$ & Sin información pública identificada \\
\hline \multirow{3}{*}{ 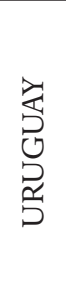 } & $\begin{array}{l}\text { Julio María } \\
\text { Sanguinetti }\end{array}$ & Ex Presidente de la República & Partido Colorado \\
\hline & José Mujica & $\begin{array}{l}\text { Ex Presidente de la República, Ex Movimiento de } \\
\text { Liberación Nacional-Tupamaros }\end{array}$ & Frente Amplio \\
\hline & Enrique Iglesias & $\begin{array}{l}\text { Ex Presidente BID, Ex Sec. Gral Iberoamericano (SEGIB), } \\
\text { Ex Sec. Ejec. CEPAL, Ex Canciller }\end{array}$ & Sin información pública identificada \\
\hline
\end{tabular}


Guerrero Soto, Nestor ei) Diplomacia preventiva (¿y ciudadana?) y cooperación para la paz en América Latina...

\begin{tabular}{|c|c|c|c|}
\hline \multirow{4}{*}{ 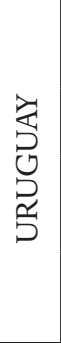 } & $\begin{array}{c}\text { Federico García } \\
\text { Vigil }\end{array}$ & Director y Compositor Musical & Sin información pública identificada \\
\hline & Ana Ribeiro & Historiadora, Escritora y Profesora & Partido Nacional \\
\hline & $\begin{array}{l}\text { Claudia } \\
\text { Amengual }\end{array}$ & Escritora & Sin información pública identificada \\
\hline & Gerardo Caetano & $\begin{array}{c}\text { Historiador, Politólogo y Presidente Consejo Superior } \\
\text { FLACSO }\end{array}$ & Sin información pública identificada \\
\hline \multirow{8}{*}{ 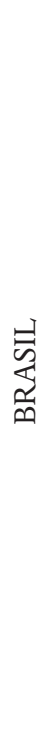 } & $\begin{array}{l}\text { Marco Aurelio } \\
\text { García }\end{array}$ & Asesor de Asuntos Exteriores de la Presidencia (2007-2016) & Partido de los Trabajadores (PT) \\
\hline & $\begin{array}{l}\text { Aloysio Nunes } \\
\text { Ferreira }\end{array}$ & Pdte. Comisión RREE Senado, Senador & Partido Social Democracia Brasileña \\
\hline & Jô Moraes & $\begin{array}{l}\text { Pdte. Comisión RREE Cámara Diputados, Diputada de la } \\
\text { República }\end{array}$ & Partido Comunista de Brasil (PCDOB) \\
\hline & $\begin{array}{l}\text { Antonino Mena } \\
\text { G. }\end{array}$ & Diplomático, Embajador & Sin información pública identificada \\
\hline & Rosita Milesi & $\begin{array}{c}\text { Representante Instituto de Migraciones y Derechos } \\
\text { Humanos }\end{array}$ & Sin Sin información pública identificada \\
\hline & $\begin{array}{l}\text { Paulo Sergio } \\
\text { Pinheiro }\end{array}$ & $\begin{array}{c}\text { Ex Sec. de Estado para DDHH, Relator ONU DD.HH., } \\
\text { Miembro Comisión de Verdad (2012), Ex Comisionado CIDH }\end{array}$ & Sin información pública identificada \\
\hline & $\begin{array}{l}\text { Ivan Marques } \\
\text { Toledo }\end{array}$ & Rector Universidad de Brasilia (UnB) & Sin información pública identificada \\
\hline & Clovis Rossi & Periodista, Columnista & Sin información pública identificada \\
\hline \multirow{12}{*}{ 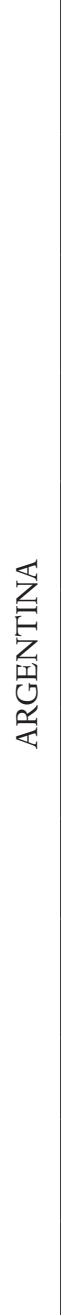 } & $\begin{array}{l}\text { Antonio Estrany } \\
\text { y G. }\end{array}$ & $\begin{array}{c}\text { Ex Pdte. Consejo Interamericano de Comercio y } \\
\text { Producción (CICYP), Vice Chairman Global Banking HSBC } \\
\text { Argentina }\end{array}$ & Sin información pública identificada \\
\hline & Jorge Taiana & $\begin{array}{l}\text { Parlamentario y Pdte. Parlamento del Mercosur, Ex } \\
\text { Ministro de RREE (2005-2010), Ex Legislador }\end{array}$ & Partido Justicialista (PJ) \\
\hline & Dante Caputo & $\begin{array}{l}\text { Diplomático, Académico, Ex Ministro de RREE (1983-1989), } \\
\text { Ex Diputado }\end{array}$ & $\begin{array}{c}\text { Unión C. Radical (UCR)/ P. Socialista } \\
\text { Pop }\end{array}$ \\
\hline & $\begin{array}{l}\text { Juan Gabriel } \\
\text { Tokatlian }\end{array}$ & Académico Internacionalista, Investigador & Sin información pública identificada \\
\hline & $\begin{array}{l}\text { José Octavio } \\
\text { Bordón }\end{array}$ & $\begin{array}{l}\text { Embajador, Académico, Ex Gobernador, Ex Diputado, Ex } \\
\text { Senador }\end{array}$ & Partido Justicialista (PJ) \\
\hline & $\begin{array}{l}\text { José Luis } \\
\text { Machinea }\end{array}$ & $\begin{array}{c}\text { Ex Pdte. Banco Central (1986-1989), Ex Ministro de } \\
\text { Economía (1999-2001) }\end{array}$ & Unión Cívica Radical (UCR) \\
\hline & Fulvio Pompeo & $\begin{array}{c}\text { Diplomático, Secretario de Asuntos Estratégicos Gobierno } \\
\text { Mauricio Macri }\end{array}$ & Sin información pública identificada \\
\hline & Carlos Álvarez & $\begin{array}{c}\text { Secretario General ALADI, Ex Diputado, Ex Vice-Pdte. de la } \\
\text { Nación (1999-2000), Ex Pdte. CRPM (2005-2009) }\end{array}$ & Frente para la Victoria \\
\hline & Rafael Follonier & $\begin{array}{c}\text { Ex Asesor y Coordinador Unidad Presidencial Gobierno } \\
\text { Néstor Kirchner, Ex Ejército Revolucionario del Pueblo (ERP) }\end{array}$ & Partido Justicialista (PJ) \\
\hline & Federico Pinedo & Senador, Pdte. (P) Senado de la Nación, Ex Diputado & Propuesta Republicana (PRO) \\
\hline & $\begin{array}{l}\text { Enrique } \\
\text { Antonioni }\end{array}$ & Sin información pública identificada & Sin información pública identificada \\
\hline & Jorge Asís & $\begin{array}{l}\text { Escritor y Periodista, Ex Embajador Gobierno Carlos } \\
\text { Menem }\end{array}$ & Sin información pública identificada \\
\hline
\end{tabular}




\begin{tabular}{|c|c|c|c|}
\hline \multirow{12}{*}{ 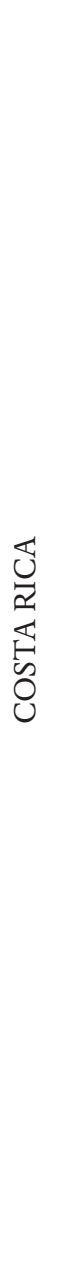 } & Alberto Salom & $\begin{array}{l}\text { Rector Universidad Nacional de Costa Rica, Pdte. Consejo } \\
\text { Nacional de Rectores (CONARE), Ex Diputado }\end{array}$ & Partido Acción Ciudadana \\
\hline & Manuel Obregón & $\begin{array}{l}\text { Músico, Ex Ministro de Cultura, Líder Mesoamericano en } \\
\text { Cultura, Medio Amb. y Desarrollo Sostenible (Fund. Avia) }\end{array}$ & Sin información pública identificada \\
\hline & $\begin{array}{l}\text { Francisco Rojas } \\
\text { Aravena }\end{array}$ & $\begin{array}{c}\text { Rector Universidad para la Paz, Sec. Gral. Flacso } \\
\text { (2004-2012), Asesor Ministerio RREE en Proceso Paz } \\
\text { Centroamérica }\end{array}$ & Sin información pública identificada \\
\hline & $\begin{array}{l}\text { Fernando } \\
\text { Naranjo }\end{array}$ & $\begin{array}{l}\text { Pdte. Grupo VOLARIS-Costa Rica, Ex Ministro de RREE, } \\
\text { Ex Ministro de Hacienda, Ex Gerente Banco Nacional }\end{array}$ & Sin información pública identificada \\
\hline & $\begin{array}{l}\text { Francisco } \\
\text { Enríquez }\end{array}$ & $\begin{array}{c}\text { Académico, Historiador Geógrafo, Ex Vice-Pdte. Instituto } \\
\text { Panamericano de Geografía e Historia }\end{array}$ & Sin información pública identificada \\
\hline & Maureen Clarke & $\begin{array}{l}\text { Diputada y Activista Derechos de la Mujer, Ex Ministra, Ex } \\
\text { Vicealcaldesa San José, Ex Pdta. Inst. Nac. de las Mujeres }\end{array}$ & Partido de Liberación Nacional (PLN) \\
\hline & Celina García & $\begin{array}{l}\text { Fundadora y Directora Centro de Estudios para la Paz } \\
\text { (CEPPA) }\end{array}$ & Partido Acción Ciudadana (PAC) \\
\hline & Patricia Mora & Académica y Diputada & Partido Frente Amplio \\
\hline & $\begin{array}{l}\text { Montserrat } \\
\text { Solano }\end{array}$ & $\begin{array}{l}\text { Defensora de los Habitantes, Miembro FIDH, Miembro } \\
\text { Comisión Int. contra la Impunidad en Guatemala } \\
\qquad(2011-2012)\end{array}$ & Independiente \\
\hline & Felisa Cuevas & Académica y Consultora & Partido Acción Ciudadana (PAC) \\
\hline & Josette Altmann & $\begin{array}{l}\text { Historiadora Política, internacionalista, Sec. Gral. Flacso } \\
(2016-2020) \text {, Ex Primera Dama (1994-1998) }\end{array}$ & Partido Acción Ciudadana (PAC) \\
\hline & Vilma Ibarra & $\begin{array}{c}\text { Periodista, Comunicadora, Ex Directora de Comunicación } \\
\text { Ministerio de RREE (1998-2002) }\end{array}$ & Sin información pública identificada \\
\hline \multirow{9}{*}{ 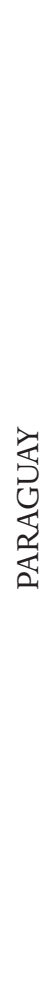 } & $\begin{array}{l}\text { Guillermo } \\
\text { Caballero V. }\end{array}$ & Empresario y Político & Partido Encuentro Nacional (PEN) \\
\hline & Emilio Camacho & $\begin{array}{l}\text { Constitucionalista, Ex Asesor Jurídico Pdte. Fernando Lugo } \\
\text { (2008-2012), Ex Pdte. Partido Encuentro Nacional (PEN) }\end{array}$ & Frente Guasú (FG) \\
\hline & $\begin{array}{l}\text { Miguel Abdon } \\
\text { Saguier }\end{array}$ & $\begin{array}{c}\text { Activista Derechos Humanos, Diplomático, Ex Ministro de } \\
\text { RREE (1999), Ex Senador }\end{array}$ & Partido Liberal Radical Auténtico \\
\hline & $\begin{array}{l}\text { José Félix } \\
\text { Fernández }\end{array}$ & $\begin{array}{l}\text { Ex Ministro de RREE (1999-2000; 2012-2013), Ex Diputado, } \\
\text { Ex Senador, Ex. Sec. Gral. ALADI }\end{array}$ & Partido Liberal Radical Auténtico \\
\hline & Evelio Fernández & $\begin{array}{l}\text { Ex Embajador, Ex Pdte. CIDH-OEA, Ex Senador, Ex } \\
\text { Ministro Asesor Político Presidencia de la República }\end{array}$ & Sin información pública identificada \\
\hline & $\begin{array}{l}\text { Domingo } \\
\text { Rivarola }\end{array}$ & Académico y Asesor, Director Flacso-Paraguay & Sin información pública identificada \\
\hline & $\begin{array}{l}\text { María José } \\
\text { Argaña M. }\end{array}$ & $\begin{array}{c}\text { Embajadora, Ex Ministra Sec. de la Mujer (2003-2008), } \\
\text { Empresaria }\end{array}$ & ANR-PC ${ }^{\star \star}$ \\
\hline & $\begin{array}{l}\text { José Antonio } \\
\text { Moreno }\end{array}$ & $\begin{array}{l}\text { Académico, Ex Ministro de RREE (2001-2003), Ex Diputado, } \\
\text { Ex Pdte. Tribunal Permanente de Revisión MERCOSUR }\end{array}$ & Sin información pública identificada \\
\hline & $\begin{array}{l}\text { Jesus Montero } \\
\text { Tirado }\end{array}$ & $\begin{array}{c}\text { Sacerdote Jesuita, Miembro Consejo Nacional de Educación } \\
\text { y Cultura }\end{array}$ & Sin información pública identificada \\
\hline
\end{tabular}

* FMLN: Frente Farabundo Martí para la Liberación Nacional / ** ANR-PC: Asociación Nacional Republicana-Partido Colorado Fuente: Elaboración propia sobre la base de fuentes públicas de información 